Proceedings

\title{
Synthesis of Novel Urethane-Dimethacrylate Monomer Containing Two Quaternary Ammonium Groups for Applications in Dentistry ${ }^{+}$
}

\author{
Marta Chrószcz * and Izabela Barszczewska-Rybarek \\ Department of Physical Chemistry and Technology of Polymers, Silesian University of Technology, \\ Strzody 9, 44-100 Gliwice, Poland; izabela.barszczewska-rybarek@polsl.pl \\ * Correspondence: marta.chroszcz@polsl.pl \\ + Presented at the 1st International Electronic Conference on Applied Sciences, 10-30 November 2020; \\ Available online: https://asec2020.sciforum.net/.
}

Published: 9 November 2020

\begin{abstract}
The development of dental composites having antibacterial properties is one of the current trends in the restorative dentistry. It is justified by the need for the secondary caries reduction that is the main reason for dental restoration failure. In this field, the growing interest is associated with the development of quaternary ammonium monomers. In this study, we synthesized a novel urethane-dimethacrylate monomer containing two quaternary ammonium groups, via the three steps synthesis route. The synthesis procedure involved the transesterification of methyl methacrylate with the use of $\mathrm{N}$-methyldiethanolamine, N-alkylation with the use of 1bromohexadecane, and synthesis of urethane-dimethacrylate resin with the use of 2,4,4trimethylhexamethylene diisocyanate. ${ }^{1} \mathrm{H}$ NMR, ${ }^{13} \mathrm{C}$ NMR, and ATR-FT IR analysis confirmed the chemical structure of the intermediate products and the structure of new urethane-dimethacrylate monomer.
\end{abstract}

Keywords: dental composites; urethane-dimethacrylate resins; antibacterial activity; quaternary ammonium groups

\section{Introduction}

Oral diseases, including dental caries and periodontitis, are considered as a global health problem that occurs in both industrialized and developing countries. It is estimated that 3.5 billion people worldwide have experienced oral diseases, among which 2.3 billion people suffered from caries of permanent teeth and 530 million children suffered from caries of primary teeth [1]. Dental caries not only inflict pain, discomfort, and disfigurement, but are also regarded as the main reason for dental restoration failure [1,2].

Dental composite restorative materials that are based on dimethacrylate resins are widely used as substitutes for tooth tissues. This arises from their mechanical and esthetical properties, which are superior when compared with the same properties of other dental materials such as amalgam or glass-ionomer cements [3]. However, in comparison to them, antibacterial properties of dimethacrylate based composites are almost imperceptible. The amount of bacteria that accumulate on their surfaces is also higher if compared to the amount of bacteria that accumulate on the teeth surfaces [2]. The phenomenon of bacteria accumulation on the surfaces of dimethacrylate-based composite materials is closely related to the polymerization shrinkage, which ranges from $2 \%$ to $5 \%$. It results from the transformation of the van der Waals forces, which exist between the monomer molecules, into the covalent bonds, which exist within the dimethacrylate polymer network. This 
transformation is responsible for tighter packing of dimethacrylate structural units. As the polymerizing system shrinks, the marginal gaps are formed and, in extreme cases, the restoration cracks. Bacteria that exist in the oral environment are able to gather in the resulting marginal gaps and cracks, and as a result of their carbohydrates metabolism, secondary caries are formed [2,3].

The current trend in dental composite materials, which arises from the previously described drawbacks, is to develop composites that have antibacterial activity. The physical admixing of various organic and inorganic antibacterial agents is the simplest way to achieve this aim. Therefore, it is the most common method of achieving dental composites with antibacterial activity $[2,4]$. However, these compounds are not able to copolymerize with dimethacrylate resins, and thus they have a tendency to leach. Additionally, they cause a decrease in the degree of curing, which negatively affects the mechanical and physico-chemical properties of the composite. Recently, there is observed a growing interest in methacrylate monomers that contain positively charged quaternary ammonium nitrogen.

Antibacterial activity of quaternary ammonium compounds is based on the disruption of bacteria electrical balance. Due to the presence of the positively charged quaternary ammonium nitrogen, they can adsorb on the surface of a negatively charged bacteria cell wall, which results in the disintegration of the cell wall electrical balance. Ions, such as calcium $\left(\mathrm{Ca}^{2+}\right)$ and potassium $\left(\mathrm{K}^{+}\right)$, and other constituents of cytoplasmic membrane, which are essential to provide proper functioning of the bacteria, are released from bacteria cell leading to its death [5].

Therefore, modern dentistry is interested in the development of new methacrylate monomers that possess the quaternary ammonium nitrogen. They are featured due to their ability to copolymerize with other dimethacrylates, constituting matrices of dental composites. They are merely a few examples of dimethacrylate monomers equipped with quaternary ammonium group described in the literature. Liang et al. synthesized new urethane-dimethacrylate monomer containing one quaternary ammonium group [6]. However, the mechanical properties of composites modified with that monomer were inappropriate, while considering application as dental materials. Thus, the aim of this study was to design the structure and synthesis procedure of novel urethanedimethacrylate monomer containing two quaternary ammonium and two methacrylate groups (Figure 1) that could be applied in dental materials as an antibacterial agent, without detrimental impact on the materials' physico-chemical and mechanical properties.

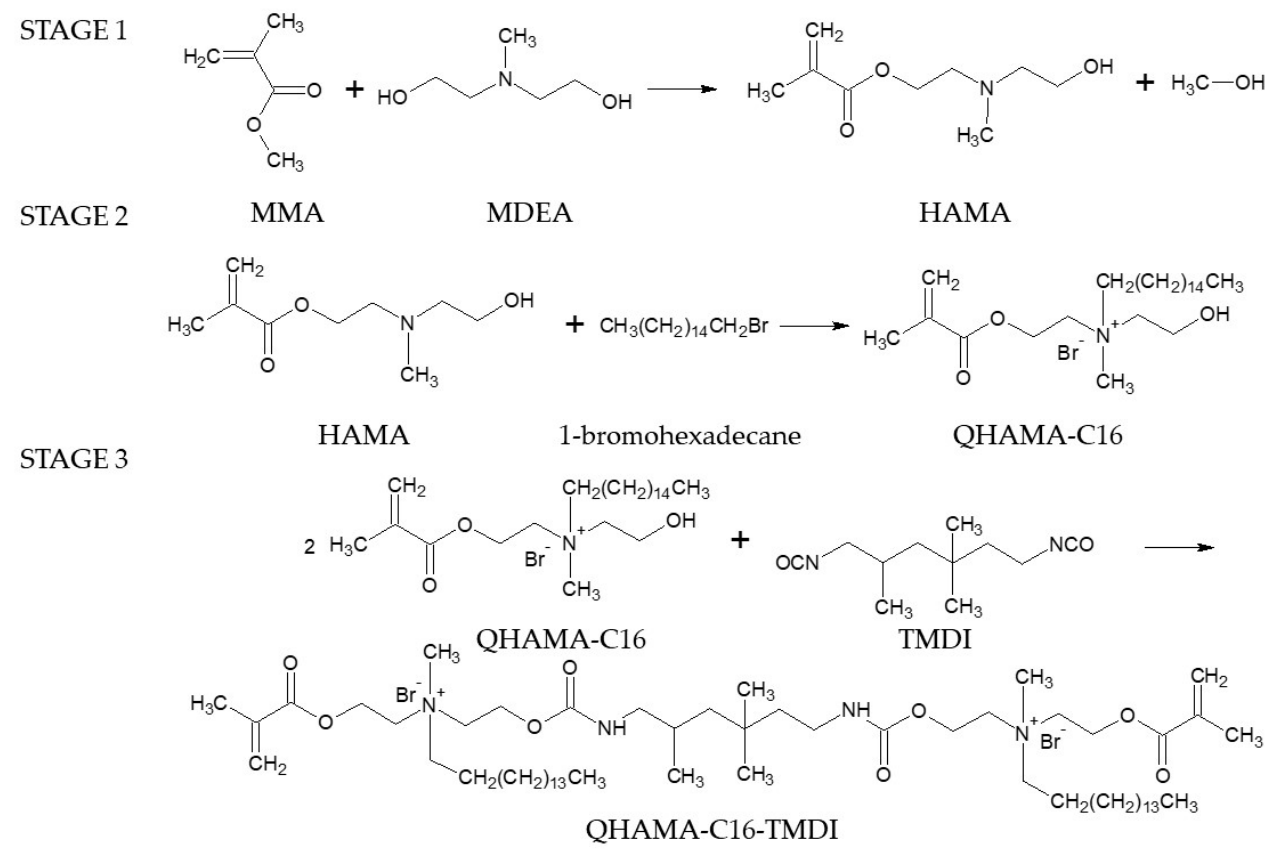

Figure 1. The synthesis route and chemical structure of the HAMA, QHAMA-C16, and QHAMAC16-TMDI synthesized in this study 2.2. 


\section{Materials and Methods}

\subsection{Materials}

1-bromohexadecane (Acros Organics, Geel, Belgium), MDEA (N-methyldiethanolamine, Acros Organics, Geel, Belgium), MMA (methyl methacrylate, Acros Organics, Geel, Belgium), TMDI (2,4,4trimethylhexamethylene diisocyanate, Tokyo Chemical Industry (TCI), Tokyo, Japan), CQ (camphorquinone, Sigma-Aldrich, St. Louis, MO, USA), DBTDL (dibutylin dilaurate, Fluka), PTZ (phenotiazine, Sigma-Aldrich, St. Louis, MO, USA), methylene chloride (POCH S.A.), toluene (Chempur, Piekary Śl., Poland), chloroform (Chempur, Piekary Śl., Poland), $\mathrm{K}_{2} \mathrm{CO}_{3}$ (potassium carbonate, Chempur, Piekary Śl., Poland), $\mathrm{MgSO}_{4}$ (magnesium sulphate, Chempur, Piekary Śl., Poland), and TMS (tetramethylsiane, Sigma-Aldrich, St. Louis, MO, USA) were used as received.

\subsection{Monomer Synthesis}

\subsubsection{Synthesis of Intermediate Product HAMA}

HAMA (Figure 1) was synthesized via transesterification reaction of $1.0 \mathrm{~mL}$ of MMA (100.12 g) with $0.67 \mathrm{~mol}$ of MDEA (79.85 g). $\mathrm{K}_{2} \mathrm{CO}_{3}$ in the amount of $8 \mathrm{wt} . \%$, was used as a transesterification catalyst. PTZ, $500 \mathrm{ppm}$, was used as an inhibitor to prevent the spontaneous radical polymerization of the methyl methacrylate group. The reaction was carried out in toluene (30 wt.\% solution), with the use of a $1000 \mathrm{~mL}$ round-bottomed flask equipped with a Vigreux distillation column. The reaction was terminated when the temperature measured at the head of the column reached $100{ }^{\circ} \mathrm{C}$, which was achieved after $2.5 \mathrm{~h}$. The reaction mixture was cooled, filtered, and washed with distilled water in a 2:1 volume ratio. Then, the aqueous layer was extracted with chloroform in a 3:1 volume ratio. The chloroform fraction was dried overnight with $\mathrm{MgSO}_{4}$, and then the solvent was removed on a rotary evaporator under reduced pressure (first at 30 and then 3 mbar). The crude product was distilled under vacuum ( 2 mbar), taking the boiling fraction of HAMA at $120-130{ }^{\circ} \mathrm{C}$. The final product yield was $19 \%$.

\subsubsection{Synthesis of QHAMA-C16}

QHAMA-C16 (Figure 1) was synthesized from 0.107 mol of HAMA (20.00 g) and 0.107 mol of 1bromohexadecane ( $32.67 \mathrm{~g})$. A mixture of HAMA and 1-bromohexadecane was introduced into the $250 \mathrm{~mL}$, three-neck flask equipped with a magnetic stirrer, reflux condenser, and thermometer. The reaction was carried out for $96 \mathrm{~h}$ at $85^{\circ} \mathrm{C}$. Crude product was washed with diethyl ether, in order to remove the unreacted 1-bromohexadecane and HAMA, several times. Then the product was dried under vacuum at $40{ }^{\circ} \mathrm{C}$. The product was obtained with a $90 \%$ yield.

\subsubsection{Synthesis of QHAMA-C16-TMDI}

QHAMA-C16-TMDI (Figure 1) was synthesized via the addition reaction of 0.1 mol of QHAMAC16 (49.25 g) and $0.05 \mathrm{~mol}$ of TMDI (10.50 g). A $50 \mathrm{wt} . \%$ solution of HAMA in methylene chloride, admixed with DBTDL (0.03 wt.\%, the catalyst) and PTZ (500 ppm, the inhibitor), was placed in a 250 $\mathrm{mL}$ three-neck flask equipped with a mechanical stirrer, thermometer, dropping funnel, and condenser. The reaction mixture was heated to $40^{\circ} \mathrm{C}$, and the $50 \mathrm{wt}$.\% solution of TMDI in methylene chloride was added dropwise for $30 \mathrm{~min}$, maintaining the temperature of $40{ }^{\circ} \mathrm{C}$. Stirring was continued for $3.5 \mathrm{~h}$ at $40^{\circ} \mathrm{C}$. After cooling, the methylene chloride was evaporated under vacuum (first at 30 mbar and then at 3 mbar). QHAMA-C16-TMDI was obtained with 100\% yield. The product was a highly viscous resin of yellow color. 


\subsection{Monomer Analysis}

\subsubsection{Nuclear Magnetic Resonance (NMR)}

${ }^{1} \mathrm{H}$ NMR and ${ }^{13} \mathrm{C}$ NMR spectra of the intermediate product as well as final monomer were recorded in the $\mathrm{CDCl}_{3}$ solution, using TMS as an internal standard. A $300 \mathrm{MHz}$ NMR spectrometer (UNITY/INOVA, Palo Alto, CA, USA) and a $600 \mathrm{MHz}$ NMR spectrometer (Varian, Palo Alto, CA, USA) were employed for these experiments.

\subsubsection{Attenuated Total Reflectance Fourier Transform Infrared Spectroscopy (ATR-FT IR)}

ATR-FT IR spectra were recorded utilizing a Spectrum Two (Perkin-Elmer, Waltham, MA, USA) spectrometer. Products were tested in a form of thin layers placed on the diamond crystal. The spectra of products were recorded with 128 scans at a resolution of $1 \mathrm{~cm}^{-1}$.

\section{Results}

QHAMA-C16-TMDI is the novel urethane-dimethacrylate monomer containing two quaternary ammonium groups, which was successfully synthesized in a three steps route (Figure 1). First, the transesterification reaction of MMA with MDEA was performed. It resulted in formation of the intermediate product HAMA, which was a tertiary amine with one methacrylate group. Then, HAMA was reacted with 1-bromohexadecane in order to transform the tertiary amine group into the quaternary ammonium group via the Menschutkin reaction. Finally, the urethane-dimethacrylate QHAMA-C16-TMDI was synthesized via the addition reaction of the hydroxyl group of QHAMAC16 (obtained in the previous step) and the TMDI isocyanate groups.

Chemical structure of intermediate and final products have been confirmed by ${ }^{1} \mathrm{H}$ NMR, ${ }^{13} \mathrm{C}$ NMR, and ATR-FT IR analysis.

The following signals were observed on the NMR and ATR-FT IR spectra of HAMA:

${ }^{1} \mathrm{H}$ NMR $\left(300 \mathrm{MHz}, \mathrm{CDCl}_{3}\right)$ : $\delta=1,95\left(\mathrm{~s}, 3 \mathrm{H}, \mathrm{C}_{3}-\mathrm{C}=\right), 2.40\left(\mathrm{~s}, 3 \mathrm{H}, \mathrm{C}_{3}-\mathrm{N}<\right), 2.60-2.90(2 \mathrm{~m}, 4 \mathrm{H}$, $\left.\mathrm{C}_{2}-\mathrm{N}<\right), 3.45$ (m, 1H, -O브), 3.55-4.40 (2m, - $\left.\underline{\mathrm{C}}_{2}-\mathrm{O}-\right)$, 5.60 i 6.20 (2m, 2H, $\left.\underline{\mathrm{C}}_{2}=\mathrm{C}-\right)$ ppm.

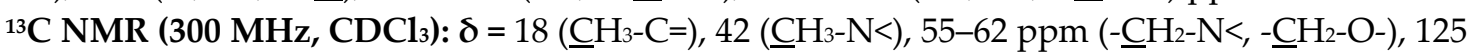
$\left(\underline{\mathrm{C}} \mathrm{H}_{2}=\right), 138(>\underline{\mathrm{C}}=), 166(\underline{\mathrm{C}}=\mathrm{O}) \mathrm{ppm}$.

ATR-FT IR: 3200-3500 (-OH), $3105\left(\mathrm{CH}_{2}=\right), 2930\left(-\mathrm{CH}_{2-}, \mathrm{CH}_{3}-\right), 1716(\mathrm{C}=0), 1638(\mathrm{C}=\mathrm{C}) \mathrm{cm}^{-1}$.

The following signals were observed on the NMR and ATR-FT IR spectra of QHAMA-C16:

${ }^{1} \mathrm{H}$ NMR (300 MHz, CDCl$)$ : $\delta=0.90\left(\mathrm{t}, 3 \mathrm{H}, \mathrm{C}_{3}-\left(\mathrm{CH}_{2}\right)_{13}-\mathrm{CH}_{2}-\mathrm{CH}_{2}-\mathrm{N}+\right), 1.35\left(\mathrm{~m}, 26 \mathrm{H}, \mathrm{CH}_{3}-\right.$ $\left.\left(\mathrm{C}_{2}\right)_{13}-\mathrm{CH}_{2}-\mathrm{CH}_{2}-\mathrm{N}+\right), 1.70\left(\mathrm{~m}, 2 \mathrm{H}, \mathrm{CH}_{3}-\left(\mathrm{CH}_{2}\right)_{13}-\underline{\mathrm{C}}_{2}-\mathrm{CH}_{2}-\mathrm{N}+\right) 1.95$ (s, 3H, $\left.\underline{\mathrm{CH}}_{3}-\mathrm{C}=\right), 3.45$ (s, 3H, $\mathrm{CH}_{3}-$ $\mathrm{N}+) 3.60\left(\mathrm{~m}, 2 \mathrm{H}, \mathrm{CH}_{3}-\left(\mathrm{CH}_{2}\right) 13-\mathrm{CH}_{2}-\mathrm{C}_{2}-\mathrm{N}+\right), 3.75-4.10\left(2 \mathrm{~m}, 4 \mathrm{H},-\underline{\mathrm{C}}_{2}-\mathrm{N}+\right), 4.20(\mathrm{~s}, 1 \mathrm{H},-\mathrm{O} \underline{\mathrm{H}}), 4.25-4.70$ $\left(2 \mathrm{~m}, 4 \mathrm{H},-\underline{\mathrm{H}}_{2}-\mathrm{O}-\right), 5.60$ i $6.10\left(2 \mathrm{~m}, 2 \mathrm{H}, \mathrm{CH}_{2}=\mathrm{C}-\right)$ ppm.

${ }^{13} \mathrm{C}$ NMR (300 MHz, CDCl 3$): \delta=14\left(\mathrm{C}_{3}-\left(\mathrm{CH}_{2}\right)_{14}-\mathrm{CH}_{2}-\mathrm{N}+\right), 18\left(\underline{\mathrm{CH}}_{3}-\mathrm{C}=\right), 22-32\left(\mathrm{CH}_{3}-\left(\underline{\mathrm{CH}}_{2}\right)_{14}-\right.$

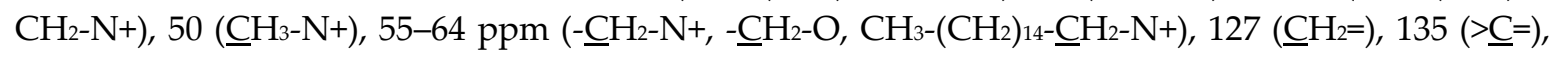
$166(\underline{\mathrm{C}}=\mathrm{O}) \mathrm{ppm}$.

ATR-FT IR: 3200-3500 (-OH), $3106\left(\mathrm{CH}_{2}=\right), 2935\left(-\mathrm{CH}_{2-}, \mathrm{CH}_{3}-\right), 1716(\mathrm{C}=0), 1636(\mathrm{C}=\mathrm{C}) \mathrm{cm}^{-1}$.

The following signals were observed on the NMR and ATR-FT IR spectra of QHAMA-C16TMDI:

${ }^{1} \mathrm{H}$ NMR $\left(600 \mathrm{MHz}, \mathrm{CDCl}_{3}\right): \delta=0.80-1.00\left(\mathrm{~m}, 15 \mathrm{H}, \mathrm{CH}_{3}-\left(\mathrm{CH}_{2}\right)_{13}-\mathrm{CH}_{2}-\mathrm{CH}_{2}-\mathrm{N}+,-\mathrm{NH}_{-}-\mathrm{CH}_{2}-\right.$ $\left.\mathrm{C}\left(\underline{\mathrm{C}}_{3}\right)_{2}-\mathrm{CH}_{2}-\mathrm{CH}\left(\mathrm{CH}_{3}\right)-\mathrm{CH}_{2}-\mathrm{CH}_{2}-\mathrm{NH}-\right),{ }_{1.25-1.35}\left(\mathrm{~m}, 52, \mathrm{CH}_{3}-\left(\mathrm{C}_{2}\right)_{13}-\mathrm{CH}_{2}-\mathrm{CH}_{2}-\mathrm{N}+\right), 1.60-1.85$ (m, $\left.9 \mathrm{H},-\mathrm{NH}-\mathrm{CH}_{2}-\mathrm{C}\left(\mathrm{CH}_{3}\right)_{2}-\mathrm{C}_{2}-\mathrm{C} \underline{\mathrm{H}}\left(\mathrm{CH}_{3}\right)-\mathrm{C}_{2}-\mathrm{CH}_{2}-\mathrm{NH}-, \mathrm{CH}_{3}-\left(\mathrm{CH}_{2}\right)_{13}-\mathrm{C}_{2}-\mathrm{CH}_{2}-\mathrm{N}+\right), 1.95$ (s, 6H, $\mathrm{C}_{3}-$ $\mathrm{C}=)$, 2.70-3.20 (m, 4H, -NH-C $\left.\underline{\mathrm{H}}_{2}-\right), 3.51\left(\mathrm{~s}, 6 \mathrm{H}, \mathrm{CH}_{3}-\mathrm{N}+\right), 3.55-3.70\left(\mathrm{~m}, 4 \mathrm{H}, \mathrm{CH}_{3}-\left(\mathrm{CH}_{2}\right){ }_{13}-\mathrm{CH}_{2}-\mathrm{C}_{2}-\mathrm{N}+\right)$, 3.90-4.30 (2m, 8H, $\left.-\underline{\mathrm{C}}_{2}-\mathrm{N}+\right), 4.50-4.80\left(2 \mathrm{~m}, 8 \mathrm{H},-\underline{\mathrm{C}}_{2}-\mathrm{O}-\right)$, 5.60 i $6.10\left(2 \mathrm{~m}, 4 \mathrm{H}, \underline{\mathrm{C}}_{2}=\right), 6.30-7.15(\mathrm{~m}$, $2 \mathrm{H},-\mathrm{N} \underline{\mathrm{H}}-\mathrm{C}=\mathrm{O}) \mathrm{ppm}$.

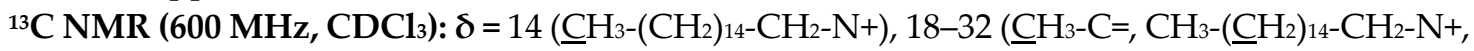

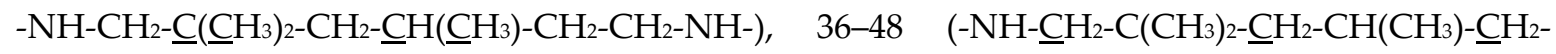

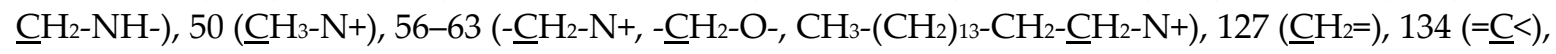
$155(-\mathrm{NH}-\underline{\mathrm{C}}=\mathrm{O}), 166$ (-ㅁO-) ppm. 
ATR-FT IR: 3221 (-NH-), 3105 ( $\left.\mathrm{CH}_{2}=\right), 2923$ (-CH2-, $\left.\mathrm{CH}_{3}-\right), 1716$ (C=O), 1639 (C=C), 1536 (-NH-) $\mathrm{cm}^{-1}$.

\section{Discussion}

In this work we developed the synthesis route of a new aliphatic urethane-dimethacrylate monomer that contains two methacrylate, two urethane, and two quaternary ammonium groups. The methacrylate groups provide the possibility of copolymerization with other dimethacrylate resins. The latter include common dental monomers, such as Bis-GMA (bisphenol A diglycidyl ether), UDMA (commonly called the urethane-dimethacrylate monomer) and TEGDMA (triethylene glycol dimethacrylate). Fully aliphatic structure of the novel monomer and the presence of urethane groups shall ensure high elasticity of its molecule, which should promote curing efficiency, mechanical strength, and impact resistance $[7,8]$. Finally, the presence of quaternary ammonium groups should provide the antibacterial activity.

The new monomer was successfully synthesized in a three steps process. First, HAMA - the monomethacrylate ended with hydroxyl functionality-was achieved via the transesterification reaction of MMA with MDEA, used in the deficiency. Then, HAMA was subjected to quaternization via the Menschutkin reaction (otherwise, N-alkylation reaction). For this purpose we used 1bromohexadecane. We decided to use alkyl bromide with sixteen carbon atoms, because several studies reported $[6,9]$ that quaternary ammonium compounds containing a sixteen carbon atoms side alkyl chain attached to the quaternary nitrogen results in the highest antibacterial activity, in comparison to the quaternary ammonium compounds containing $\mathrm{N}$-alkyl chain with higher or lower number of carbon atoms. This is mainly associated with the interactions between the quaternary ammonium compound and the lipids that build up the bacteria cytoplasmic membrane. It was reported that the length of hydrocarbon chains that create those lipids is about 16 carbon atoms [10]. Thus, the quaternary ammonium monomers containing a side alkyl chain of similar length can interact with the bacteria lipids more efficiently than compounds containing an alkyl side chain of shorter or longer lengths. The final stage, which involved the synthesis of urethane-dimethacrylate, was conducted with the use of QHAMA-C16 and TMDI. TMDI has been chosen as a diisocyanate due to its industrial application in the synthesis of the UDMA resin that is currently used as a matrix component of common composite dental restorative materials, due to its good physico-chemical and mechanical properties [11].

The chemical structure of the newly designed monomer should benefit in several aspects. QHAMA-C16-TMDI can be recognized as full-featured comonomer in the composite matrix curing process. The presence of two methacrylate groups ensures the possibility of the monomer incorporation into the polymer network with both ends. On the contrary, quaternary ammonium monomers with one methacrylate group can be incorporated into the polymer network with only one end. It means that the monomer body works as a pendant chain, causing a plasticizing effect. In the consequence, the polymer network loses its tightness, which reflects in its mechanical weakening [7]. Therefore, monomethacrylates can be used in small amounts. Huang et al. [12] confirmed this effect and revealed that the chemical modification of the dimethacrylate matrix with quaternary ammonium monomethacrylate negatively affects mechanical properties of the composite. Additionally, it is worth noting that dimethacrylate monomers have a lower tendency to leaching than monomethacrylate monomers. It can be deduced then that the composite based solely on dimethacrylates will have lower cytotoxicity than that containing a certain amount of monomethacrylate [7]. The second asset of our new monomer stems from the presence of two quaternary ammonium groups. It was reported that the antibacterial activity of polycationic compounds is related to the amount of quaternized nitrogen atoms in their structures [13]. In comparison to the monomers that contain one quaternary ammonium group, lower amount of the QHAMA-C16-TMDI might be sufficient to achieve comparable antibacterial activity. It can be substantial in accordance to the composite's physico-chemical and mechanical characteristics, because lower amounts of currently used dimethacrylate based resins will have to be replaced by the quaternary ammonium monomer. Our predictions derive from the study of Liang et al. [6] in which 
they reported that the addition of monomers with quaternary ammonium groups significantly increased composite water sorption and solubility.

Author Contributions: conceptualization and methodology: I.B.-R. and M.C.; investigation: M.C.; resources: I.B.-R. and M.C.; data curation: M.C.; writing-original draft preparation: M.C.; writing-review: I.B.-R.; writing - editing: I.B.-R. and M.C.; visualization: M.C.; supervision and project administration-I.B.-R.; funding acquisition: M.C. Both authors have read and agreed to the published version of the manuscript.

Funding: This research was funded by the Polish Budget Founds for Scientific Research in 2020 as core funding for R\&D activities in the Silesian University of Technology-funding for young scientists, grant number 04/040/BKM20/0128.

Conflicts of Interest: The authors declare no conflict of interest.

\section{References}

1. World Health Organization. Oral Health. Available online: https://www.who.int/news-room/factsheets/detail/oral-health (accessed on 14 October 2020).

2. Ali, S.; Sangi, L.; Kumar, N.; Khurshid, Z.; Zafar, M.S. Evaluating antibacterial and surface mechanical properties of chitosan modified dental resin composites. Technol. Health Care 2020, 28, 165-173, doi:10.3233/THC-181568.

3. Lin, G.S.S.; Abdul Ghani, N.R.N.; Ismail, N.H.; Singbal, K.P.; Yusuff, N.M.M. Polymerization Shrinkage and Degree of Conversion of New Zirconia-Reinforced Rice Husk Nanohybrid Composite. Eur. J. Dent. 2020, 14, 448-455, doi:10.1055/s-0040-1713951.

4. Khurshid, Z.; Zafar, M.; Qasim, S.; Shahab, S.; Naseem, M.; AbuReqaiba, A. Advances in Nanotechnology for Restorative Dentistry. Materials 2015, 8, 717-731, doi:10.3390/ma8020717.

5. Tashiro, T. Antibacterial and Bacterium Adsorbing Macromolecules. Macromol. Mater. Eng. 2001, 286, 6387, doi:10.1002/1439-2054(20010201)286:2<63::AID-MAME63>3.0.CO;2-H.

6. Liang, X.; Huang, Q.; Liu, F.; He, J.; Lin, Z. Synthesis of Novel Antibacterial Monomers (UDMQA) and Their Potential Application in Dental Resin. J. Appl. Polym. Sci. 2013, 129, 3373-3381, doi:10.1002/APP.39113.

7. Barszczewska-Rybarek, I.M. A Guide through the Dental Dimethacrylate Polymer Network Structural Characterization and Interpretation of Physico-Mechanical Properties. Materials 2019, 12, 4057, doi:10.3390/ma12244057.

8. Barszczewska-Rybarek, I. The role of molecular structure on impact resistance and bending strength of photocured urethane-dimethacrylate polymer networks. Polym. Bull. 2017, 74, 4023-4040, doi:10.1007/s00289-017-1944-z.

9. Li, F.; Weir, M.D.; Xu, H.H.K. Effects of Quaternary Ammonium Chain Length on Antibacterial Bonding Agents. J. Dent. Res. 2013, 92, 932-938, doi:10.1177/0022034513502053.

10. Komagata, K.; Suzuki, K.I. Lipid and Cell-Wall Analysis in Bacterial Systematics. Methods Microbiol. 1988, 19, 161-207, doi:10.1016/S0580-9517(08)70410-0.

11. Gajewski, V.E.S.; Pfeifer, C.S.; Fróes-Salgado, N.R.G.; Boaro, L.C.C.; Braga, R.R. Monomer Used in Resin Composites: Degree of Conversion, Mechanical Properties and Water Sorption/Solubility. Braz. Dent. J. 2012, 23, 508-514.

12. Huang, Li.; Yu, F.; Sun, X.; Dong, Y.; Lin, P.; Yu, H.; Xiao, Y.; Chai, Z.; Xing, X.; Chen, J. Antibacterial activity of a modified unfilled resin containing a novel polymerizable quaternary ammonium salt MAE-DB. Sci. Rep. 2016, 6, 33858, doi:10.1038/srep33858.

13. Youdovin-Farber, I.; Golenser, J.; Nurit, B.; Weiss, E.; Domb, A. Quaternary Ammonium Polyethyleneimine: Antibacterial Activity. J. Nanomater. 2010, 2010, 826343, doi:10.1155/2010/826343.

Publisher's Note: MDPI stays neutral with regard to jurisdictional claims in published maps and institutional affiliations.

(C) 2020 by the authors. Licensee MDPI, Basel, Switzerland. This article is an open access article distributed under the terms and conditions of the Creative Commons Attribution (CC BY) license (http://creativecommons.org/licenses/by/4.0/). 